\title{
0 realismo está morto. Viva o realismo!
}

\section{Rui Pina Coelho}

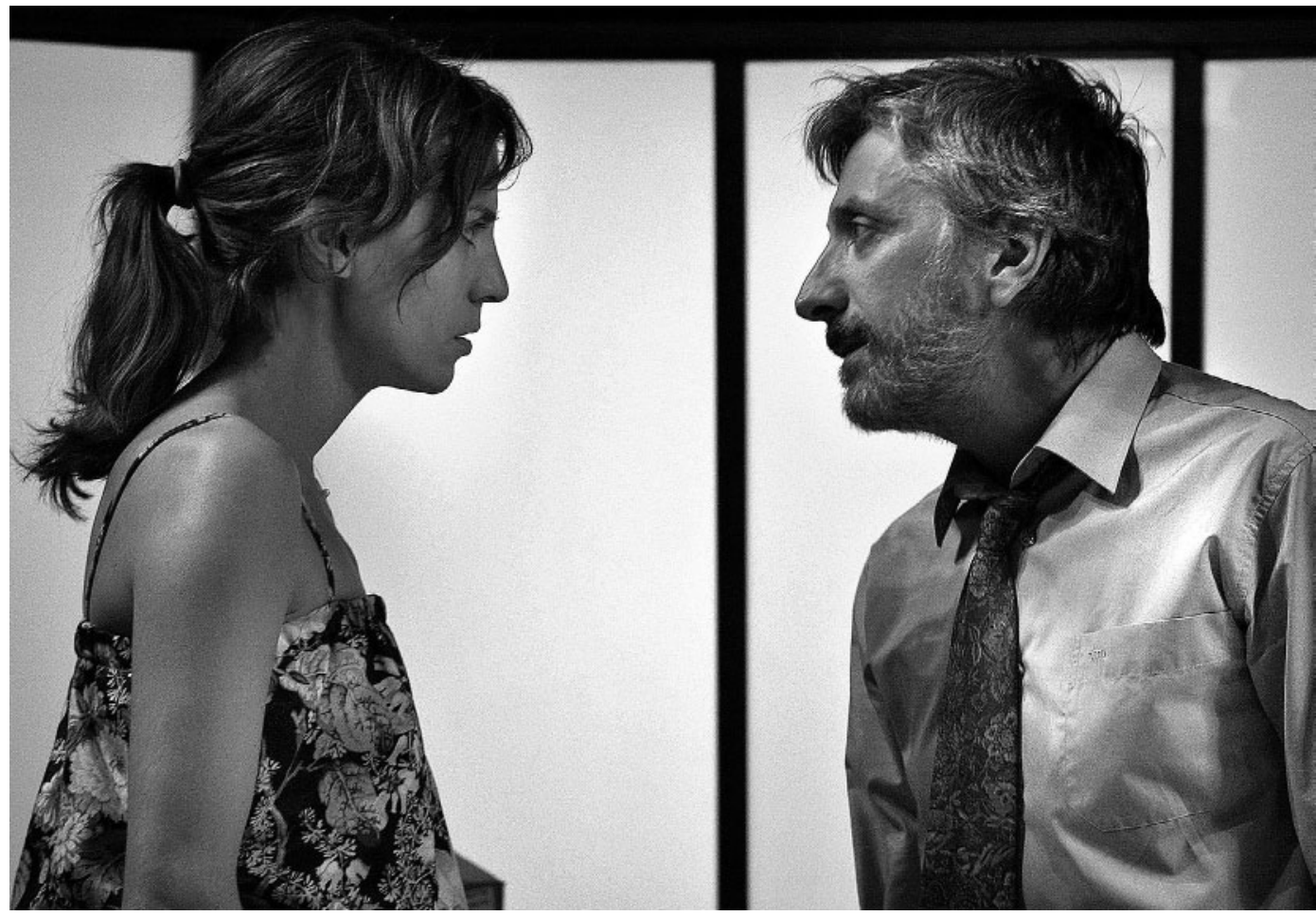

Blackbird,

de David Harrower, enc. Tiago Guedes, TNDMII, 2010 (Isabel Abreu e Miguel Guilherme), fot. Margarida Dias.

Titulo: Blackbird (2005). Autor: David Harrower. Tradução e encenação: Tiago Guedes. Cenário e figurinos: Joana Rosa. Desenho de luz: Nuno Meira. Sonoplastia: Rui Dâmaso. Interpretação: Isabel Abreu, Miguel Guilherme e Constança Rosado / Filipa Rebelo / Margarida Lopes. Produção: Take It Easy | TNDMII. Local e data de estreia: Teatro Nacional D. Maria II, 14 de Janeiro de 2010.

Título: Num dia igual aos outros (On an Average Day, 2002). Autor: John Kolvenbach. Tradução: Gonçalo Waddington, Marco Martins, Miguel Castro Caldas e Nuno Lopes. Encenação: Marco Martins. Cenografia: Artur Pinheiro. Figurinos: Isabel Carmona. Desenho de luz: Nuno Meira. Interpretação: Gonçalo Waddington e Nuno Lopes. Produção: TNDMII. Local e data de estreia: Teatro Nacional D. Maria II, 11 de Março de 2010.

Há muito que o realismo vive a prazo e com uma certidão de óbito passada. Em alguns circuitos teatrais ganhou até contornos francamente pejorativos, frequentemente conotado com um certo conservadorismo estético e associado a recursos discursivos menos consonantes com a vertigem e a liberdade pós-moderna ou pós-dramática. Porém, a história do teatro, das últimas décadas do século XIX em diante, deve algumas das suas mais assinaláveis datas ao realismo e à representação realista. Fundado sobre a ideia de que a arte deve erguer um espelho para a natureza e exigindo um código de representação mimética implicada na ideia dramática aristotélica, ainda hoje, na actualidade, o tratamento realista motiva difusas criações pertinentes e actuantes. Atravessando todo o século XX, o realismo pluralizou-se e foi sendo adjectivado de maneira múltipla com vista a melhor poder dar conta das mutações que o mundo e a cena foram sofrendo. Realismo psicológico, realismo mágico, realismo filosófico, realismo abstracto, realismo social, realismo socialista, realismo crítico, realismo épico, hiper-realismo, são apenas algumas das muitas designações que têm ajudado a descrever o amplo campo de acção de uma estética de representação do real. A somar a estas variáveis, há que acrescentar a uma breve cartografia do realismo a sua relação com o naturalismo, termo gémeo e muitas vezes seu sinónimo. Visando distinguir estes sempre intrincados termos - naturalismo e realismo -, Paul Allain e Jen Harvie, em The Routledge Companion to Theatre and Performance, acrescentam a uma longa discussão: 


$$
\begin{array}{r}
\text { Blackbird, } \\
\text { de David Harrower, } \\
\text { enc. Tiago Guedes, } \\
\text { TNDMII, } 2010 \\
\text { (Isabel Abreu } \\
\text { e Miguel Guilherme), } \\
\text { fot. Margarida Dias. }
\end{array}
$$

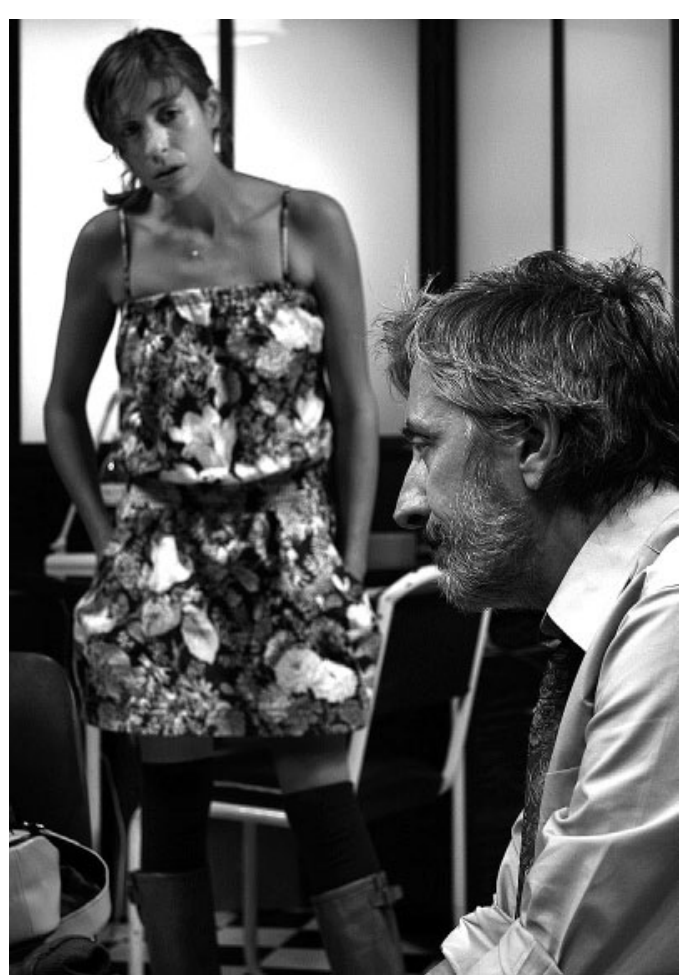

Alguns autores sugerem que o naturalismo presta maior atenção que o realismo ao ambiente social como uma influência para as personagens, e que o realismo profere uma estética mais crítica e menos imitativa ou ilusionista, mas estas distinções são demasiado subtis e discutiveis para que possam ser operativas hoje e é dificil alcançar um consenso neste assunto. (Allain \& Hervie 2006: 178, tradução minha).

E mais adiante, para concluir:

\footnotetext{
Tem sido repetidas vezes afirmado que a representação segundo a estética naturalista reforça mais do que desafia o status quo, e é por isso considerada politica (e também ideologicamente) conservadora. Mas o naturalismo [e o realismo] e a sua história são complexos e não podem ser comparados com formas mais experimentais de maneira simplesmente binária. 0 trabalho de dramaturgos com mensagens politicas ou sociais, implicitas ou explicitas - desde o kitchen sink drama do pós-Segunda Grande Guerra, aos textos de Arthur Miller ou Tennessee Williams, até às peças de David Hare - contestam essa ideia. (Ibidem: 179)
}

E, com efeito, há uma tradição na dramaturgia contemporânea - com particular e fulgurante exemplo no caso anglo-saxónico - que rumina e reedita a abordagem realista e que a vai desabrigando de um alegado conservadorismo estético e ideológico, interpelando crítica e inventivamente o real em todas a suas variantes. $E_{1}$ o que me importa particularmente aqui, esta tradição parece ter encontrado, em Lisboa, um porto de abrigo seguro na sala estúdio do Teatro Nacional D. Maria II (considerando especialmente as temporadas de 2009 e 2010). Se Harper Reagan, de Simon Stephens, e Ego (Into de Silent Land), de Paul Brook, eram atravessados por uma certa recreação formal (o espaço, no primeiro; o tempo, no segundo; o uso de uma linguagem meticulosamente carpinteirada, a meio caminho entre a poesia e o coloquial, em ambos), Blackbird, de David
Harrower, e Num dia igual aos outros (On an Average Day), de John Kolvenbach, erguem-se numa arquitectura narrativa de clara implantação realista. Os espaços onde a acção decorre são meticulosamente pormenorizados, o ambiente é verosimilmente realista, pejado de objectos extraídos de um quotidiano referenciável (latas, embalagens, jornais, caixotes), todos com uma volumetria e densidade real. Com efeito, os cenários e figurinos de Joana Rosa e a sonoplastia de Rui Dâmaso (em Blackbird), a cenografia de Artur Pinheiro e os figurinos de Isabel Carmona (Num dia igual aos outros) e os desenhos de luz de Nuno Meira (em ambos os espectáculos) são de um apuro extremo e de uma observância realista absolutamente rigorosa. Da mesma maneira, tematicamente, as duas peças trabalham em torno de questões prementes da actualidade: o abuso sexual de menores, no caso do texto de David Harrower a desagregação do núcleo familiar e o espectro da crise, na obra de John Kolvenbach. Duas obras que se inscrevem numa tradição realista de claro comentário social e intervenção pública.

Blackbird, de David Harrower, dramaturgo revelado em Portugal pelos Artistas Unidos (Facas nas galinhas, em 2000) é alegadamente inspirado no caso de Toby Studebaker, um ex-marine norte-americano que, em 2003, fugiu com uma rapariga de doze anos que conhecera numa sala de conversação, na Internet. Ainda que Harrower tenha tomado este caso como ponto de partida, o que esta peça propõe não é exactamente uma reconstituição de factos. Antes executa uma desmontagem dos argumentos e das razões apresentadas por cada uma das partes, criando uma nova ficção dramática. Na peça de Harrower, Ray e Una conhecem-se numa festa em casa dos pais da pequena rapariga, então com 12 anos. A relação entre ambos cresce em segredo, levando a um desfecho que porá Ray na prisão por vários anos. A acção dramática tem início no momento em que Una, agora com 27 anos, vem confrontar o seu abusador, que 


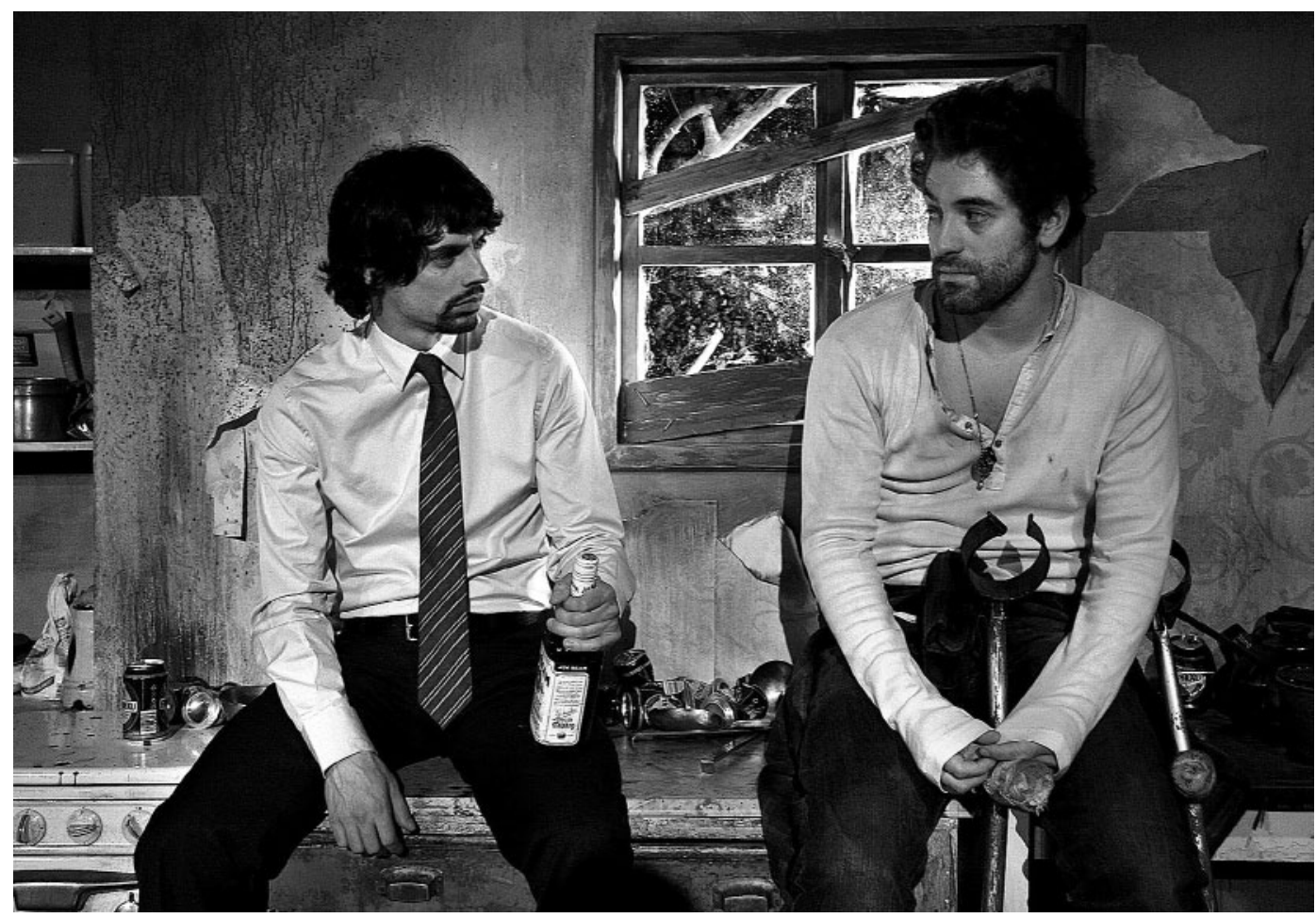

Num dia igual aos outros de John Kolvenbach, enc. Marco Martins, TNDMII, 2010 (Gonçalo Waddington e Nuno Lopes), fot. Margarida Dias.

entretanto refizera a sua vida numa outra cidade e com um outro nome. Una encontra Ray (agora Peter Trevelyan) no seu local de trabalho e conversam - sozinhos e isolados dos olhares dos colegas - numa espécie de sala de convívio, desarrumada e com vestígios de comida e utilização permanente.

Com esta moldura, fica instalada a arena para um confronto entre vitima e abusador. Contudo, o que Harrower faz magistralmente é nunca ceder a moralismos imediatos, compondo duas personagens "bestialmente" eficazes na exposição dos seus argumentos, o que faz com que a relação de poder esteja sempre em permanente oscilação. Ainda que o encontro sexual entre as duas personagens não possa nunca deixar de ser entendido como um abuso, Harrower quebra a finura dos argumentos e instala nessa fractura uma insidiosa dúvida. Como tudo o que sabemos é dito em discurso directo pelas personagens, nunca sabemos quem distorce a realidade nem quem a reconstrói. Ou seja, nunca é verdadeiramente claro se houve abuso, amor, manipulação, afecto, ciúme, atracção, despeito, mal-entendido... Dependendo do narrador, conta-se uma diferente versão dos acontecimentos, ambas tremendamente eficazes. $E_{1}$ tratando-se este de um tema em que normalmente não há grandes dúvidas sobre que partido se tomar, Blackbird é perigosamente subversivo.

Muito justamente, Tiago Guedes ergue um espectáculo numa encenação que resiste a comentar o texto, respeitando-o em todas as suas insinuações. Para isso, direcciona o espectáculo para uma ênfase no trabalho dos actores, fazendo assentar neles toda a dinâmica e todas as correlações de poder. E nisso, Isabel Abreu e Miguel Guilherme não são nada menos que brilhantes, percorrendo com mestria maior todo o sinuoso mapa de emoções das duas complexas personagens. Isabel Abreu compõe uma Una que se apresenta como uma frágil vítima, controlando-se a custo, mas que, a espaços, insinua uma mulher portentosa e tremendamente cativante, segura e dominadora. Miguel Guilherme sabe insinuar o monstro à espreita, astuto e manipulador, mas sabe também apresentar um simpático homem de meia-idade ferido pela vida. Em ambos, nunca é certo qual o retrato final que querem deixar no espectador, jogando sempre e muito sustentadamente na ambiguidade. Do mesmo modo, ambos encetam um strip-tease emocional, descarnando defesa após defesa, argumento após argumento, até chegarem a um estado de autêntica nudez sentimental. Mas, uma e outra vez, o carrossel argumentativo de Harrower faz com que estejam permanentemente a iniciar novo embate.

Em Num dia igual aos outros, a primeira peça do dramaturgo norte-americano John Kolvenbach a ser apresentada em Portugal, é usada a mesma estratégia de regresso ao passado. Assim, neste caso temos dois irmãos que foram separados abruptamente na adolescência e que se reencontram após 15 anos. Um, Jack (Gonçalo Waddington) bem sucedido e bem vestido, aparece a Robert (Nuno Lopes), na casa onde este ainda vive e que já foi a sua casa de familia. Embora ainda sejam visíveis os antigos objectos que animariam a vida familiar comum (um triciclo, algum mobiliário, tachos e panelas), a cozinha em que a acção se desenrola está dominada pelo espectro da pobreza, sujidade, solidão e crise em que Robert se encontra, pejada de louça suja, paredes escamadas, caixas, e dezenas de jornais espalhados por todo o lado (jornais onde procura insanamente notícias do pai que os abandonou a ambos). Faminto, pobre, quase iletrado, "esguio, tem um ar adoentado" (na didascália de Kolvenbach, embora não se confirme no corpo atlético de Nuno Lopes), vive de pequenos expedientes. Por outro lado, Jack, articulado, elegante, visita o irmão por um motivo que permanecerá escondido até praticamente ao final da peça. Contudo, a réplica inicial instala a peça numa outra zona temática. Assim, diz Robert: "Jack. Eu não fiz aquilo, Jack". E "aquilo", viremos nós a saber, foi 
Num dia igual aosoutros de John Kolvenbach, enc. Marco Martins, TNDMII, 2010 (Gonçalo Waddington e Nuno Lopes), fot. Margarida Dias.

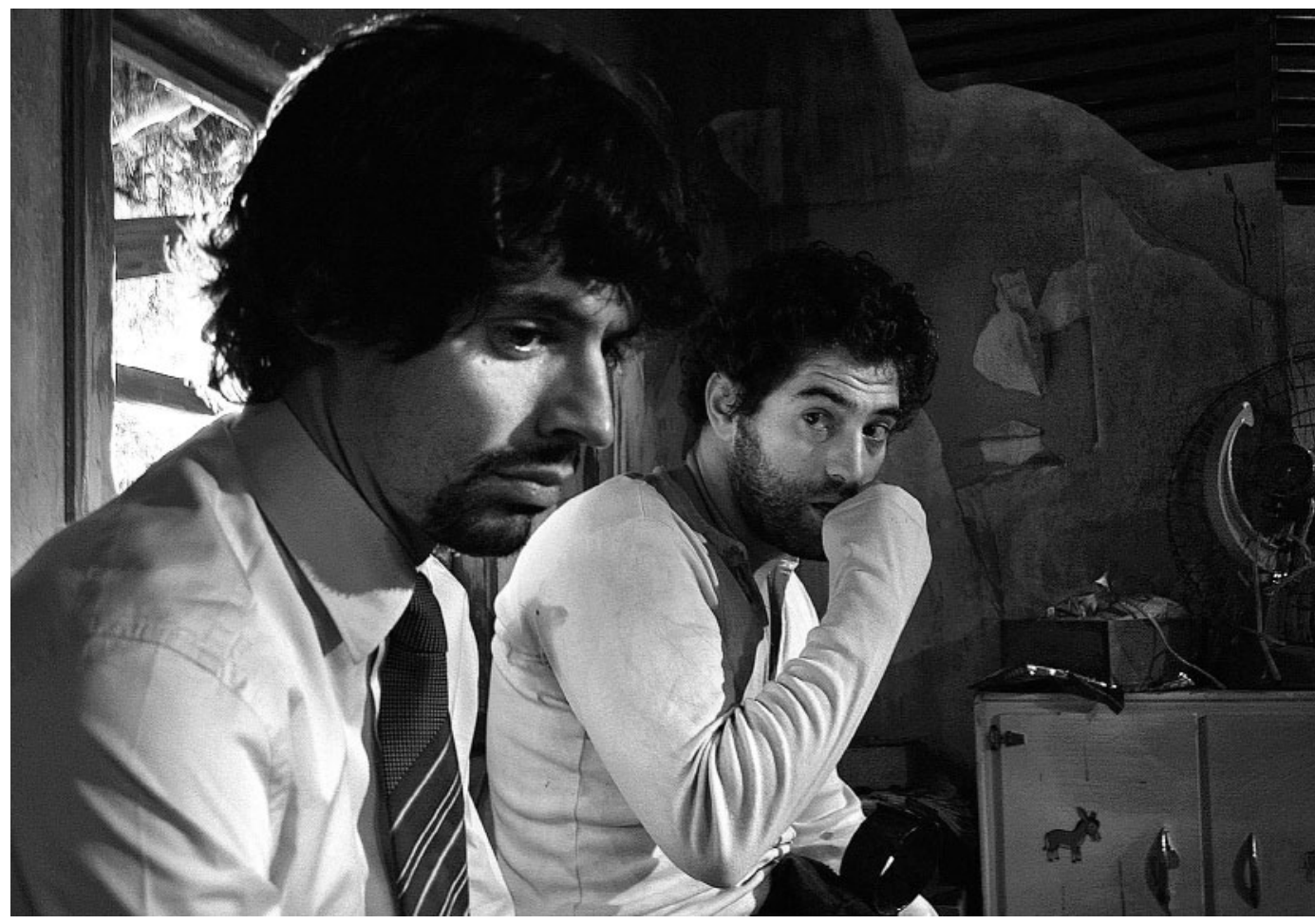

uma tentativa de homicidio: Robert, que apanhara uma boleia de um camionista que o assedia, responde violentamente atirando-o para fora do camião. $\mathrm{E}_{1}$ se aparentemente o texto gira em torno deste acontecimento, estando a inesperada presença de Jack ali justificada por ter visto na televisão notícias sobre o crime de Robert, a verdadeira natureza do reencontro dos dois irmãos será bem mais perturbante. Assim, depois de imitar o pai e de ter abandonado a sua própria familia, Jack dirigia-se a Robert em busca de uma qualquer redenção possivel.

Sob a ameaça da intoxicação (que os actores parecem mesmo procurar, bebendo consecutivas cervejas),

Waddington e Lopes dão uso a ricas e variadas paletas expressivas, proporcionando uma verdadeira escalada temperamental. Jogando sob o signo da contenção, do humor nervoso, da tensão indisfarçável e da violência latente, os dois actores carburam, a álcool, reminiscências e confissões, acabando tudo num violento confronto físico, impecavelmente representado.

Marco Martins, habituado que está a trabalhar sobre a intensidade emocional e sobre o insondável no humano, ataca este depurado exemplo de realismo psicológico assombrado com a dissolução da estrutura familiar com discrição, numa encenação de impecável urdidura e limpeza, fazendo concentrar (tal como Tiago Guedes em Blackbird) as atenções no jogo dos actores. Estes, jovens e brilhantes, afiançam a todo o espectáculo uma intensidade assinalável, em interpretações de rigor ímpar.

Em ambos os espectáculos apresentados na sala estúdio do Teatro Nacional D. Maria II, e tal como é espectável em propostas de carácter realista, a visibilidade da intervenção autoral do encenador é diminuida, aparecendo reforçado o virtuosismo dos actores (e, refirase, das equipas de cenografia, figurinos e iluminação). Isabel Abreu, Miguel Guilherme, Gonçalo Waddington e Nuno Lopes, todos eles - e por razões diferentes - são intérpretes de qualidade maior na cena nacional e garantem, pela excelência dos seus trabalhos nestes espectáculos, a relevância dos temas propostos e, sobretudo, a ilusão de realidade pretendida. Assim, ainda que a viver a prazo e apesar da sua fraca reputação, 0 realismo vai ainda proporcionando um teatro necessário.

\section{Referência bibliográfica}

ALLAIN, Paul / HARVIE, Jen (2006), The Routledge Companion to Theatre and Performance, London and New York, Routledge. 